\title{
Trypanosomes in Eastern and Central European bats
}

\author{
Petr Linhart ${ }^{1}$, Hana Bandouchova ${ }^{1}$, Jan Zuka22,3, Jan Votypka ${ }^{4,5}$, Tomasz Kokurewicz ${ }^{6}$, \\ Heliana Dundarova ${ }^{7}$, Grzegorz Apoznanski' ${ }^{6}$, Tomas Heger ${ }^{1}$, Aneta Kubickova ${ }^{1}$, \\ Monika Nemcova ${ }^{1}$, Vladimir Piacek ${ }^{1}$, Jana Sedlackova ${ }^{1}$, Veronika Seidlova ${ }^{1}$, \\ Hana Berkova², Vladimir Hanzal ${ }^{8}$, Jiri Pikula ${ }^{1}$ \\ ${ }^{1}$ University of Veterinary and Pharmaceutical Sciences Brno, Faculty of Veterinary Hygiene and Ecology, \\ Department of Ecology and Diseases of Zoo Animals, Game, Fish and Bees, Brno, Czech Republic \\ ${ }^{2}$ Czech Academy of Sciences, Institute of Vertebrate Biology, Brno, Czech Republic \\ ${ }^{3}$ Masaryk University, Faculty of Science, Department of Botany and Zoology, Brno, Czech Republic \\ ${ }^{4}$ Charles University, Faculty of Science, Department of Parasitology, Prague, Czech Republic \\ ${ }^{5}$ Czech Academy of Sciences, Biology Centre, Institute of Parasitology, Ceské Budějovice, Czech Republic \\ ${ }^{6}$ Wrocław University of Environmental and Life Sciences, Faculty of Biology and Animal Science, \\ Institute of Biology, Department of Vertebrate Ecology and Paleontology, Wrocław, Poland \\ ${ }^{7}$ Bulgarian Academy of Sciences, Institute of Biodiversity and Ecosystem Research, Sofia, Bulgaria \\ ${ }^{8}$ Nature Conservation Agency of the Czech Republic, Prague, Czech Republic
}

Received October 28, 2019

Accepted January 28, 2020

\begin{abstract}
Bats are presumed primary hosts of trypanosomes of the subgenus Schizotrypanum, including the human pathogen Trypanosoma cruzi. As such, research on bat trypanosomes has been focused on South America, where Chagas disease is a serious issue. While the majority of European studies have been performed in the United Kingdom, there is virtually no data available for Eastern and Central parts of Europe. To address this, the present study aims to identify and assess the prevalence and pathogenicity of trypanosomes in bats sampled in the Czech Republic, Bulgaria, and Poland. Blood collected from 381 adult bats of eight species was tested for presence of trypanosomes using nested polymerase chain reactions. To assess possible impacts of trypanosome parasites on the health status of their hosts, haematological and biochemical analyses were performed for 56 greater mouse-eared bats (Myotis myotis) emerging from hibernacula and 36 females of the same species from summer colonies. The overall prevalence of the two trypanosome species detected (T. dionisii and $T$. vespertilionis) was $27 \%$, with a significantly higher prevalence in the Czech Republic compared to the other countries studied. Significant differences in bat trypanosome prevalence in different European countries appear to be connected with presence or absence of possible vectors in summer roosts. No impact of trypanosomes on haematology and blood chemistry parameters was detected in Trypanosoma-positive greater mouse-eared bats. Though T. dionisii infection in bats appears asymptomatic, long-term health consequences still need to be studied in greater detail.
\end{abstract}

Blood parasites, Schizotrypanum, Trypanosoma dionisii, Trypanosoma vespertilionis, Chiroptera, health status

Bats host several trypanosome species of the subgenus Schizotrypanum, including the important human pathogen Trypanosoma cruzi that causes Chagas disease, a serious issue in Latin America. As such, most studies on bat trypanosomes and their host-parasite relationships have been focused on South American bat and trypanosome species (Lisboa et al. 2008; Cottontail et al. 2014; Ramírez et al. 2014).

In Europe, research concerning bat trypanosomes was mainly performed in the UK in the early part of the twentieth century (Petrie 1905; Coles 1914) and the 1970s and 80s (Baker et al. 1972; Gardner and Molyneux 1988). These classic morphological studies were later followed by molecular research (Lord 2010; Hamilton et al. 2012). Knowledge on the presence of bat trypanosomes in the rest of Europe, however, is limited

Address for correspondence:

Hana Bandouchova

Department of Ecology and Diseases of Zoo Animals, Game, Fish and Bees

University of Veterinary and Pharmaceutical Sciences

Phone: +420541562653

Palackeho tr. 1946/1, 612 42, Brno, Czech Republic 
and/or anecdotal. While it is presumed that bat trypanosomes are highly prevalent in European bat species, only the UK data are available, meaning that we lack evidence on the infection status in Eastern and Central European bats. Likewise, there is a lack of data on trypanosome pathogenicity in bats. As no adverse effects associated with this infection have yet been reported, trypanosomes of the subgenus Schizotrypanum are considered non-pathogenic for bats (Lord and Brooks 2014). On the other hand, bats are exposed to many stressors during their lifetime, e.g. allocation of resources during physiological states such as hibernation torpor or lactation, and these could influence the outcome of any infection (Bandouchova et al. 2009; Kopp et al. 2018). During hibernation, immune system functions are limited (Bouma et al. 2010), while lactation imposes high energy demands on the female (Harshman and Zera 2007). The cryptic lifestyle of nocturnal mammals has also contributed to the lack of knowledge regarding the impact of infection on bat health. To date, no studies have yet been published on the impact of trypanosomes on bats during hibernation or lactation.

The aim of the present study, therefore, is a) to improve our knowledge of the prevalence of bat trypanosomes in European countries, and b) to analyse haematology and blood chemistry parameters in order to assess the impact of trypanosomes on hibernating and lactating greater mouse-eared bats (Myotis myotis).

\section{Materials and Methods}

\section{Animals}

Between 2015 and 2019, blood samples of 381 bats of eight vespertilionid bat species were collected in the Czech Republic, Bulgaria, and Poland. Bats were netted at swarming sites, maternity roosts or while emerging from hibernacula at the end of the hibernation period. The number of blood samples collected from the different species were as follows: the greater mouse-eared bat $(M$. myotis, $\mathrm{n}=180)$, the noctule bat (Nyctalus noctula, $\mathrm{n}=100)$, the lesser mouse-eared bat (Myotis blythii, $\mathrm{n}=42)$, the Daubenton's bat (Myotis daubentonii, $\mathrm{n}=25)$, the Geoffroy's bat (Myotis emarginatus, $\mathrm{n}=8$ ), the Natterer's bat (Myotis nattereri, $\mathrm{n}=13$ ), the brown long-eared bat (Plecotus auritus, $\mathrm{n}=7$ ) and the Barbastelle bat (Barbastella barbastellus, $\mathrm{n}=6$ ). A detailed overview of the sampling sites, periods of sampling and site-specific number of individuals is summarised in Table 1.

\section{Sampling sites}

Bats were sampled at five localities in the Czech Republic, two in Bulgaria and one in Poland. Sampling in the Czech Republic was performed in the Moravian Karst including one swarming site (the Kateřinská cave [49.3607006N, 16.7102508E]), two hibernacula (the Sloupsko-Šošůvské caves [49.4104556N, 16.7390147E] and the Býčí skála cave [49.3074614N, 16.6947844E]), and in the Czech Karst (Malá Amerika mine [49.9545178N, $14.1760375 \mathrm{E}]$ ). Sampling at maternity roosts was performed on two summer colonies (church attics in Doubravník [49.4256094N, 16.3518378E] and Otaslavice [49.3848658N, 17.0676067E]). Ambient temperatures ranged from 5.5 to $8.8{ }^{\circ} \mathrm{C}$ at the hibernacula, 35 to $55^{\circ} \mathrm{C}$ in the church attics containing summer colonies, and 12 to $20{ }^{\circ} \mathrm{C}$ at the swarming sites. Hibernating noctules were sampled in captivity when held in an artificial hibernaculum (temperature $8^{\circ} \mathrm{C}$ ) and swarming noctules were caught in Brno while emerging from tree holes.

In Poland, sampling was performed at the end of hibernation in the Nietoperek bat reserve (underground corridors of an abandoned German military fortification from the central sector of the Międzyrzecz Fortified Front in western Poland [52.3956606N, 15.5120972E]) with ambient temperatures ranging from 6.1 to $9.9^{\circ} \mathrm{C}$.

Bulgarian swarming sites were in the Rhodope Mountains (Lednitzata ice cave [41.6497364N, 24.5339131E]) and in the Danubian Plain, north-eastern Bulgaria (the Orlova chuka cave with a constant year-round temperature of $\left.14^{\circ} \mathrm{C}[43.5899 \mathrm{~N}, 25.9603 \mathrm{E}]\right)$.

\section{Collection of blood samples}

Blood samples were collected using methods described by Bandouchova et al. (2018) and Pikula et al. (2017). Polymerase chain reaction (PCR) analysis required $20 \mu \mathrm{l}$ of blood, while additional $100 \mu \mathrm{l}$ of blood were collected from 56 greater mouse-eared bats emerging from hibernacula and 36 lactating females of the same species from two maternity colonies for haematology and biochemistry measurements. Prior to release, the bats were provided with fluids and energy by oral administration of glucose and saline. All animals were handled so as to minimise stress. Both the sampling of bats and blood collection were performed in accordance with Czech Law No. 114/1992 on Nature and Landscape Protection, based on permits 1662/MK/2012S/00775/MK/2012, 866/JS/2012 and 00356/KK/2008/ AOPK issued by the Agency for Nature Conservation and Landscape Protection of the Czech Republic. Collection and sampling of bats in Bulgaria and Poland was authorized through permit Nos. 645/13.08/2015, 153/11.07/2016, WPN-I-6205.10.2015.AI, WPN-I-6205.13.2019.MZ and Resolution Nr. 45/2015 and 14/2018. The authors of the study 
Table 1. List of bat species, countries, localities and number of individuals sampled in this study.

\begin{tabular}{|c|c|c|c|c|}
\hline Species & Country & Hibernation sampling sites & Swarming sampling sites & Maternity colonies \\
\hline \multirow{6}{*}{$\begin{array}{l}\text { Myotis } \\
\text { myotis }\end{array}$} & $\mathrm{CZ}$ & Moravian Karst $2015(\mathrm{n}=39)$ & Moravian Karst $2015(\mathrm{n}=14)$ & Doubravnik church $2016(n=21)$ \\
\hline & & Moravian Karst $2018(\mathrm{n}=19)$ & & Otaslavice church $2016(n=23)$ \\
\hline & & Mala Amerika $2018(\mathrm{n}=19)$ & & \\
\hline & PL & Nietoperek $2016(\mathrm{n}=20)$ & & \\
\hline & & Nietoperek $2019(\mathrm{n}=20)$ & - & - \\
\hline & BG & - & Lednitzata cave $2015(\mathrm{n}=5)$ & - \\
\hline \multirow{2}{*}{$\begin{array}{l}\text { Nyctalus } \\
\text { noctula }\end{array}$} & $\mathrm{CZ}$ & Brno $2016(n=51)$ & Brno $2016(n=13)$ & - \\
\hline & & Brno $2018(n=36)$ & & \\
\hline \multirow[t]{2}{*}{ Myotis blythii } & $i \quad \mathrm{BG}$ & - & Lednitzata cave $2015(\mathrm{n}=20)$ & \\
\hline & & & Orlova chuka $2016(\mathrm{n}=22)$ & - \\
\hline \multirow{3}{*}{$\begin{array}{l}\text { Myotis } \\
\text { daubentonii }\end{array}$} & PL & Nietoperek $2015(\mathrm{n}=8)$ & & \\
\hline & & Nietoperek $2019(\mathrm{n}=13)$ & - & - \\
\hline & BG & - & Lednitzata cave $2015(n=4)$ & - \\
\hline \multirow{2}{*}{$\begin{array}{l}\text { Myotis } \\
\text { nattereri }\end{array}$} & PL & Nietoperek $2019(\mathrm{n}=7)$ & - & - \\
\hline & $\mathrm{BG}$ & - & Lednitzata cave $2015(n=6)$ & - \\
\hline $\begin{array}{l}\text { Myotis } \\
\text { emarginatus }\end{array}$ & BG & - & Lednitzata cave $2015(\mathrm{n}=8)$ & - \\
\hline $\begin{array}{l}\text { Plecotus } \\
\text { auritus }\end{array}$ & BG & - & Lednitzata cave $2015(\mathrm{n}=7)$ & - \\
\hline $\begin{array}{l}\text { Barbastella } \\
\text { barbastellus }\end{array}$ & PL & Nietoperek $2019(n=6)$ & - & - \\
\hline
\end{tabular}

CZ - Czech Republic; PL - Poland; BG - Bulgaria

were authorized to handle free-ranging bats in agreement with the Czech Certificate of Competency No. CZ01341 ( 117 , Act No. 246/1992). All sampling in Poland was supervised by trained personnel: Dr Tomasz Kokurewicz (PolLASA Certificate no. 2413/2015) and Mgr Grzegorz Apoznański (PolLASA Certificate no. 2360/2015).

Detection of trypanosomes in blood samples

Total genomic deoxyribonucleic acid (DNA) was isolated from the blood samples using a DNA isolation kit (High Pure PCR Template Preparation Kit, Roche, Switzerland), according to the protocol recommended by the manufacturer. We used the nested PCR analysis protocol for Trypanosoma spp. detection described in Seward et al. (2017). The PCR was performed using Mini Opticon (Bio-Rad, USA), with reactions undertaken in a $20 \mu 1$ reaction mixture containing $10 \mu \mathrm{l} 2 \times$ EmeraldAmp Max PCR Master Mix (Takara, Japan), $4 \mu \mathrm{l}$ water, $0.5 \mu \mathrm{l}$ of each primer $(10 \mathrm{pmol} / \mu \mathrm{l})$ and a $5 \mu \mathrm{l}$ aliquot of isolated DNA in the first round, and $5 \mu \mathrm{l}$ of the PCR product from the first round instead of DNA in the second round.

All DNA amplicons were directly sequenced, the sequences being edited and compared with the GenBank database via a BLAST (Basic Local Alignment Search Tool) search (https://blast.ncbi.nlm.nih.gov/Blast/). Representative sequences were deposited under GenBank acc. nos. MN604027, MN604028, MN604041, MN604082, MN607591 (18S rRNA). To assess phylogenetic relationships, we compared our 18S rRNA T. dionisii and T. vespertilionis sequences with sequences of T. dionisii (AJ009151, FN599058, LC326397), T. vespertilionis (AJ009166), T. erneyi (JN040989) and T. livingstonei (KF192984) isolates published in GenBank database. We used BioEdit sequence alignment editor v7.0.9.0 (Hall 1999) and MrBayes program v3.2 (Ronquist et al. 2012) for Bayesian inference using Markov chain Monte Carlo (MCMC) methods to estimate the posterior distribution of model parameters. The phylogenetic tree was constructed with the use of FigTree graphic viewer v1.4.4 (Rambaut 2010). Infection intensity was checked on blood smears in greater mouse-eared bats (M. myotis) and noctule bats (N. noctula). 
Haematology and blood chemistry

Blood parameters were measured using the EC8+ cartridge on a VetScan i-STAT analyser (Abaxis, USA). Parameters measured included the $\mathrm{pH}$ value $(\mathrm{pH})$, partial pressure carbon dioxide $\left(\mathrm{pCO}_{2} \mathrm{kPa}\right)$, total carbon dioxide $\left(\mathrm{tCO}_{2} \mathrm{mmol} / \mathrm{l}\right)$, bicarbonate $\left(\mathrm{HCO}_{3} \mathrm{mmol} / \mathrm{l}\right)$, base excess $(\mathrm{BE}, \mathrm{mmol} / \mathrm{l})$, sodium $(\mathrm{Na}, \mathrm{mmol} / \mathrm{l})$, chloride $(\mathrm{Cl}, \mathrm{mmol} / \mathrm{l})$, potassium $(\mathrm{K}, \mathrm{mmol} / \mathrm{l})$, anion gap (AnGap, $\mathrm{mmol} / \mathrm{l})$, blood urea nitrogen (BUN, $\mathrm{mmol} / \mathrm{l})$, glucose (Glu, mmol/l), haematocrit (Hct, 1/l) and haemoglobin (Hb, g/l).

\section{Statistical analysis}

Chi-square test was used to compare differences in the prevalence of trypanosomes between sexes, localities, periods of sampling and host species, as well as differences in prevalence between the noctule bats T. dionisii and T. vespertilionis.

Normal distribution of variables for the whole haematology and blood chemistry parameter datasets was tested using Kolmogorov-Smirnov and Shapiro-Wilk tests. All blood parameters were normally distributed with the exception of $\mathrm{Na}, \mathrm{K}, \mathrm{BUN}, \mathrm{pCO}_{2}$ and $\mathrm{pH}$. The one-way analysis of variance (ANOVA) and post hoc least significant difference (LSD) tests were used to assess trypanosome impact and sampling period. As a significant impact of the sampling period was confirmed in two subsets, i.e. hibernation and lactation, these were analysed separately. Normality was then re-checked using Kolmogorov-Smirnov and Shapiro-Wilk tests. In hibernating animals, all parameters were normally distributed with the exception of $\mathrm{K}, \mathrm{BUN}$ and $\mathrm{pCO}_{2}$, while $\mathrm{K}, \mathrm{CL}, \mathrm{HCO}$, $\mathrm{BE}$ and $\mathrm{tCO}_{2}$ were non-normally distributed in lactating females. One-way ANOVA and post hoc LSD tests were used to assess differences in haematology and blood chemistry parameters between Trypanosoma-positive and -negative animals. Non-normally distributed parameters were tested for using Kruskal-Wallis ANOVA. All analyses were performed in Statistica v.13.2.

\section{Results}

Of the 381 individual blood samples collected from the eight bat species, 103 proved positive for Trypanosoma spp. Direct DNA sequencing of the amplified small subunit (SSU) revealed a predominance of $T$. dionisii. Prevalence of $T$. dionisii was 31.8, 28.0, and $9.5 \%$ in greater mouse-eared, noctule and lesser mouse-eared bats. A second parasite species, $T$. vespertilionis, was only confirmed in nine noctule bats. Sequence comparisons revealed a percentual identity of $>99.6 \%$ with $T$. dionisii and $T$. vespertilionis isolates in the GenBank. Phylogenetic relationships of Trypanosoma dionisii and Trypanosoma vespertilionis $18 \mathrm{~S}$ rRNA sequences isolated from the greater mouse-eared bat (M. myotis) and the noctule bat (N. noctule) are illustrated in Fig. 1 .

Chi-square tests confirmed significant differences between (i) $T$. dionisii prevalence in the Czech Republic (32.3\%) and Bulgaria $(8.3 \% ; P<0.001)$ and Poland $(16.2 \%$; $P=0.007)$; (ii) prevalence of $T$. dionisii $(28 \%)$ and $T$. vespertilionis $(9 \%)$ in noctule bats $(P<0.001)$; (iii) swarming prevalence of $T$. dionisii in $M$. myotis from the Czech Republic $(50.0 \%)$ compared to its sibling species lesser mouse-eared bat from Bulgaria $(9.5 \%$; $P=0.001$ ); and (iv) $T$. dionisii prevalence in greater mouse-eared bats from the Czech Republic (35.1\%) compared with Daubenton's bats from Poland $(9.5 \% ; P=0.025)$ during hibernation. While there was no difference in infection prevalence between sexes during any of the sampling periods, a significantly higher prevalence was confirmed between hibernating bats $(29.8 \%)$ and those caught during the swarming period $(18.2 \% ; P=0.028)$. A detailed overview of Schizotrypanum prevalence in bat species, countries and sampling periods is provided in Table 2.

One-way ANOVA and post hoc LSD test undertaken on the whole dataset revealed a significant impact of the sampling period on all haematology and blood chemistry parameters except $\mathrm{Cl}$, Hct, $\mathrm{pCO}_{2}$ and $\mathrm{Hb}$. Separate analyses of the hibernating and lactating subsets indicated no differences in haematology and blood chemistry parameters between Trypanosoma-positive and -negative bats. Infection intensity was very low with up to 4 trypomastigotes per the whole blood smear. The results of haematology and blood chemistry analysis on Trypanosoma-positive and -negative bats are summarised in Tables 3 and 4. 


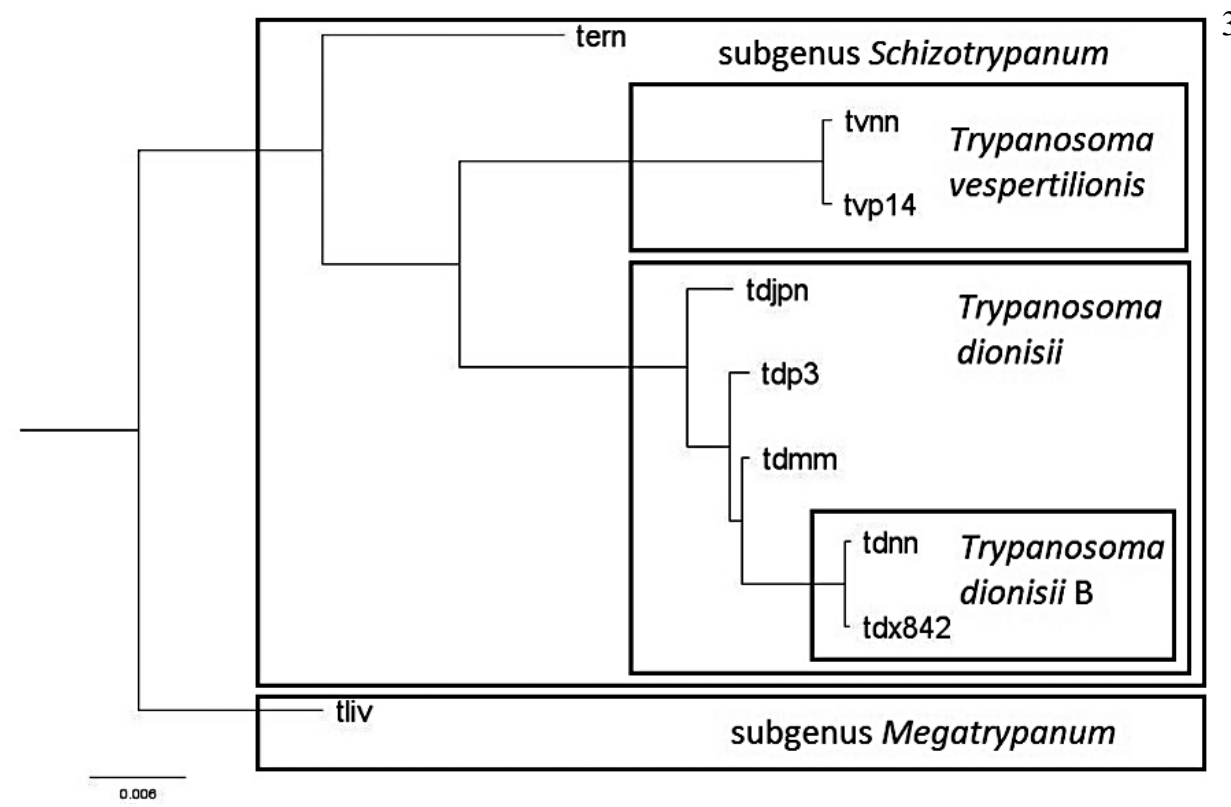

Fig. 1. Phylogenetic relationships of bat trypanosomes Trypanosoma dionisii and Trypanosoma vespertilionis isolated from Myotis myotis and Nyctalus noctula in this study.

Isolates of 18S rRNA from GenBank database: tern - Trypanosoma (Schizotrypanum) erneyi isolate from Mops condylurus, Mosambique (GenBank JN040989); tvp14 - Trypanosoma vespertilionis P14 isolate from Pipistrellus pipistrellus, United Kingdom (GenBank AJ009166); tdjpn - Trypanosoma dionisii isolate from Miniopterus fuliginosus, Japan (GenBank LC326397); tdp3 - Trypanosoma dionisii P3 isolate from Pipistrellus pipistrellus, United Kingdom (GenBank AJ009151); tdx842 - Trypanosoma dionisii x842 isolate from Nyctalus noctula, United Kingdom (GenBank FN599058) and tliv - Trypanosoma (Megatrypanum) livingstonei isolate from Hipposideros caffer, Mosambique (GenBank KF192984).

Isolates of 18S rRNA obtained in the present study: tvnn - Trypanosoma vespertilionis isolate from Nyctalus noctula, Czech Republic (GenBank MN604082); tdmm - Trypanosoma dionisii isolate from Myotis myotis, Poland (GenBank MN604028) and tdnn - Trypanosoma dionisii isolate from Nyctalus noctula, Czech Republic (GenBank MN604041).

\section{Discussion}

Our results indicate a high prevalence rate for trypanosomes of the subgenus Schizotrypanum in the Czech Republic, Bulgaria and Poland, especially as regards T. dionisii, which was dominant in all the bat species tested. Our T. dionisii isolates from noctules $(N$. noctula) are closely related to $T$. dionisii B clade from the UK, previously confirmed to be more closely related with $T$. dionisii isolates from Brazil (Hamilton et al. 2012). This result supports the idea of connected population of noctules within Europe or migration of noctules across long distances within their range. A second species, T. vespertilionis, was only confirmed in noctule bats, with prevalence significantly lower than that for $T$. dionisii. Both $T$. dionisii and $T$. vespertilionis were confirmed in noctules from the same colony, though no case of co-infection was recorded. Differences in the prevalence of these trypanosome species may have resulted from interspecific competition within the bat hosts or within invertebrate vectors, as both species utilise the same ecological niche. A similar effect has previously been described in co-infection with different strains of T. brucei (Balmer et al. 2009).

Ectoparasites can play an important role in transmission of infectious agents in bats (Lucan et al. 2016). It is generally assumed that two blood-sucking heteropteran bug species adapted to bats, Cimex pipistrelli and C. lectularius, play an important role in transmission 


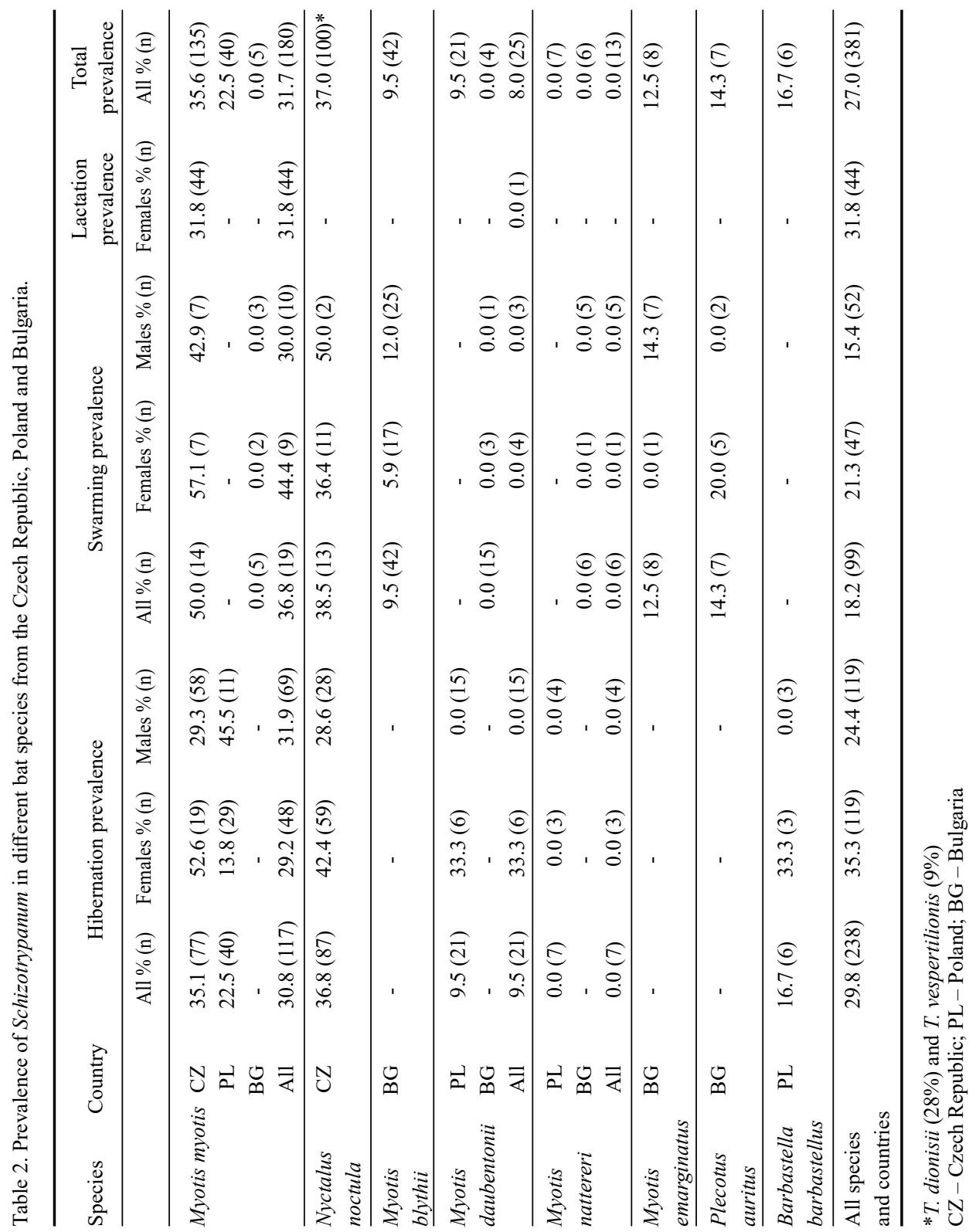

of bat trypanosomes in Europe. In Central Europe, these nidicolous ectoparasites are strongly bound to summer maternity colonies of M. myotis and summer shelters or bat boxes used by N. noctula or Pipistrellus spp., with Cimex spp. having been confirmed in ca. $80 \%$ of summer M. myotis colonies in the Czech Republic (Balvín et al. 2014). We found approximately three times higher trypanosome prevalence in noctules and greater mouseeared bats in the Czech Republic compared to Bulgaria and Poland, suggesting that these two species play an important role in maintaining Shizotrypanum trypanosomes in Central 


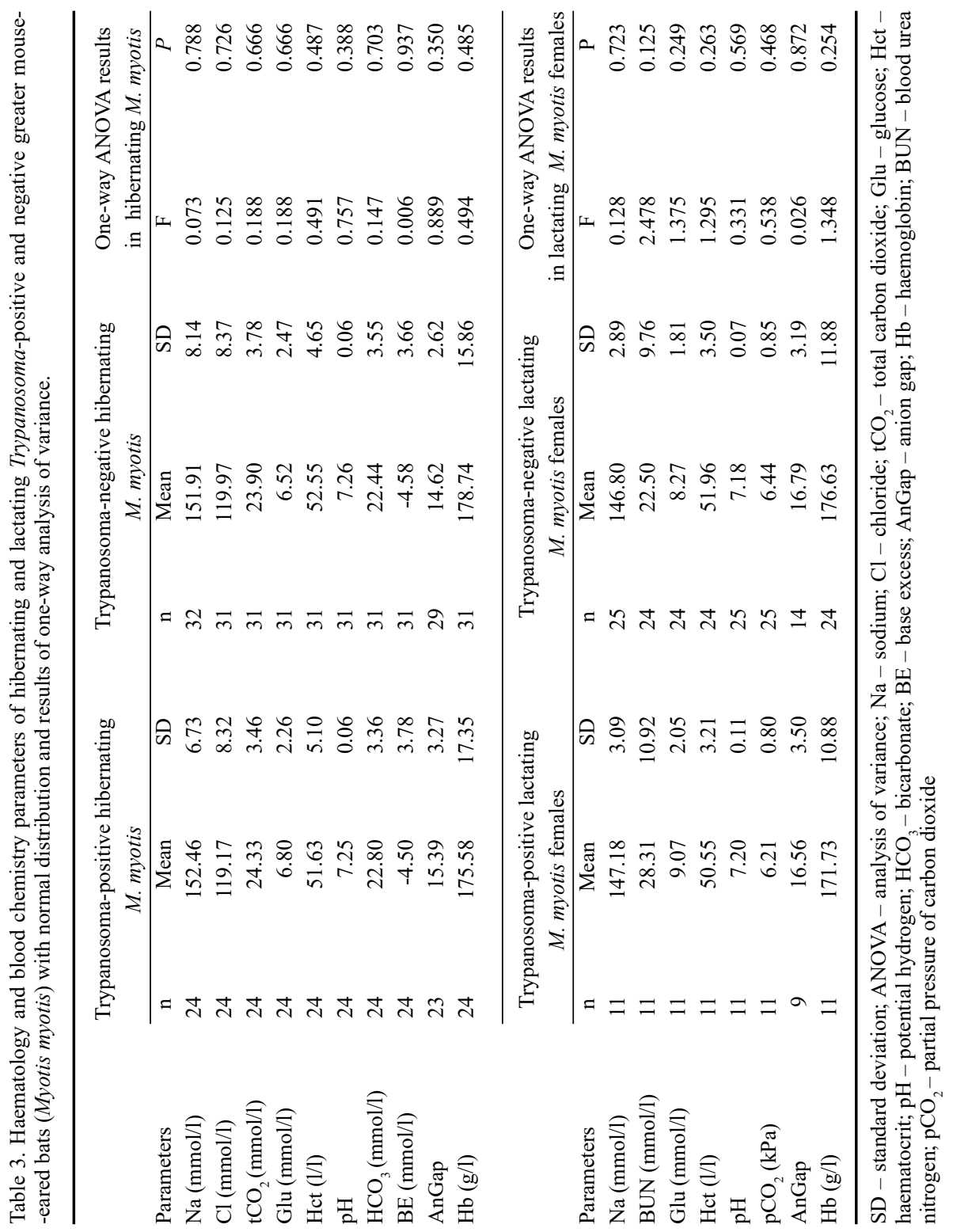

Europe. Noctules in particular play a crucial role as these migratory bats are thought to spread Cimex spp. between European bat colonies (Balvín et al. 2012). In comparison, Cimex spp. are relatively rare in bats from the Balkan region, probably due to sub-optimal conditions in their summer roosts, which are predominantly found in caves (Balvín et al. 2014). A similar situation also appears true for Poland, though it should be noted that the only survey of Polish Cimex spp. was undertaken during hibernation, hence no data are available for maternity roosts (Haitlinger and Łupicki 2008). On the other hand, a number of Polish greater mouse-eared bat maternity roosts are found in underground 


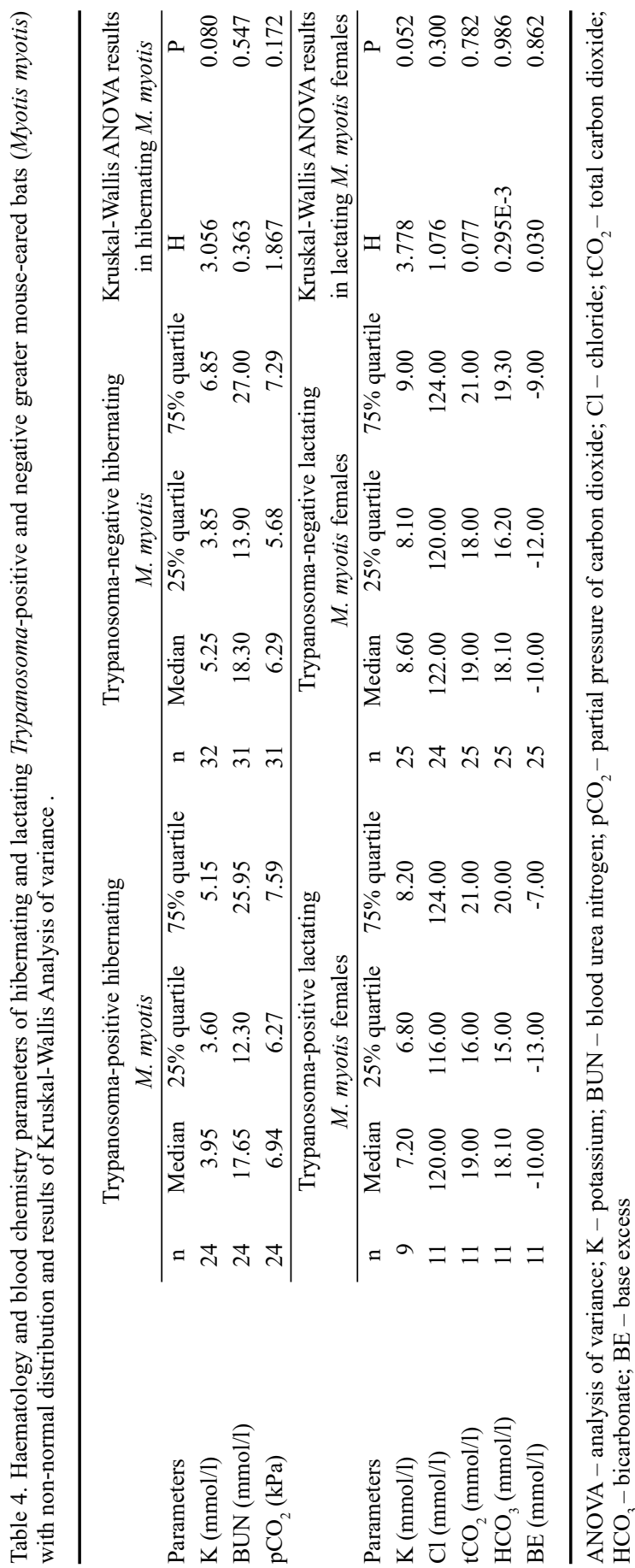

sites, e.g. Nietoperek, which is used by bats for both hibernation and as a maternity roost site, despite the availability of attics (Postawa and Gas 2009). In Poland, therefore, we might also expect microclimatic conditions to impact on presence of Cimex spp. in underground maternity roosts, similar to the Balkan region. These observations correspond with our own results showing a significantly lower prevalence of bat trypanosomes in Bulgaria and Poland compared to the Czech Republic.

As the lesser mouse-eared bat has similar ecological requirements to its sibling species the greater mouse-eared bat (Arlettaz at al. 1997), a similar trypanosome prevalence would be expected. Surprisingly, however, we recorded a significantly lower prevalence in lesser mouse-eared bats, again probably due to the absence of vectors in Bulgarian summer roosts (Balvín et al. 2014). We also noted significantly higher trypanosome prevalence in hibernating over swarming bats, though this was probably due to differences in the number of each species in the hibernation and swarming groups and their countries of origin.

As summer roosts comprise almost exclusively female bats and their offspring, females might be expected to be more exposed to vectors than males; however, we found no significant differences in $T$. dionisii prevalence between males and females. A possible explanation for this may be that bats are infected as juveniles or through vertical transmission from mother to offspring, as previously described for $T$. cruzi (Muñoz et al. 2009). Howard et al. (2014), for example, reported 
the likelihood of T. cruzi transmission from mother to foetus at around 5\% (Howard et al. 2014). Like humans, bats have a haemochorial placenta (Carter and Mess 2008); hence, the barrier between maternal and foetal blood is similar in bats and humans, though minimal compared to some other mammalian species. Vertical transmission represents a long-term advantage for the pathogen in terms of its spread within host populations, with parasites undergoing vertical transmission generally benign towards their host (Ewald 1995). Nevertheless, we propose that a detailed survey be undertaken to confirm this hypothesis.

The hypothesis of benign behaviour by bat Schizotrypanum trypanosomes is also supported by the lack of any significant difference in haematology and blood chemistry parameters between Trypanosoma-positive and -negative animals. Neither hibernating nor lactating Trypanosoma-positive bats showed any impact of infection on the measured blood parameters. On the other hand, Schizotrypanum trypanosomes are known to form cystic structures in bat organs and tissues, including the heart and skeletal muscles (Molyneux 1991). This has also been confirmed in T. cruzi (Cardoso et al. 2016; Ponte-Sucre 2016), where chronic effects involving tissue damage caused by the host's own antibodies targeting encysted developmental trypanosome stages were the main pathogenic mechanism in Chagas disease (Lozano et al. 2017). The same effects may also be expected in long-lived bats as a consequence of long-term infection. We suggest that additional studies examining antibody-mediated effects of Schizotrypanum on bats will be needed to assess whether such a process affects particular species at the population level.

\section{Acknowledgements}

We are grateful to Dr. Kevin Roche for correction and improvement of the English text. This study was supported by the Czech Science Foundation (Grant No. 17-20286S) and the Internal Grant Agency of the University of Veterinary and Pharmaceutical Sciences Brno (Grant No. 230/2017/FVHE).

\section{References}

Arlettaz R, Perrin N, Hausser J 1997: Trophic resource partitioning and competition between the two sibling bat species Myotis myotis and Myotis blythii. J Anim Ecol 66: 897-911

Baker JR, Green SM, Chaloner LA, Gaborak M 1972: Trypanosoma (Schizotrypanum) dionisii of Pipistrellus pipistrellus (Chiroptera): intra- and extracellular development in vitro. Parasitology 65: 251-263

Balmer O, Stearns SC, Schötzau A, Brun R 2009: Intraspecific competition between co-infecting parasite strains enhances host survival in African trypanosomes. Ecology 90: 3367-3378

Balvín O, Ševčík M, Jahelková H, Bartonička T, Orlova M, Vilímová J 2012: Transport of bugs of the genus Cimex (Heteroptera: Cimicidae) by bats in western Palaearctic. Vespertilio 16: 43-54

Balvín O, Bartonička T, Simov N, Paunovic M, Vilímová J 2014: Distribution and host relations of species of the genus Cimex on bats in Europe. Folia Zool 63: 281-289

Bandouchova H, Sedlackova J, Pohanka M, Novotny L, Hubalek M, Treml F, Vitula F, Pikula J 2009: Tularemia induces different biochemical responses in BALB/c mice and common voles. BMC Infect Dis 9: 101

Bandouchova H, Bartonička T, Berkova H, Brichta J, Kokurewicz T, Kovacová V, Linhart P, Piacek V, Pikula J, Zahradníková A, Zukal J 2018: Alterations in the health of hibernating bats under pathogen pressure. Sci Rep 8: 6067

Bouma HR, Carey HV, Kroese FG 2010: Hibernation: the immune system at rest? J Leukoc Biol 88: 619-624

Cardoso MS, Reis-Cunha JL, Bartholomeu DC 2016: Evasion of the immune response by Trypanosoma cruzi during acute infection. Front Immunol 6: 659

Carter AM, Mess A 2008: Evolution of the placenta and associated reproductive characters in bats. J Exp Zool B Mol Dev Evol 310: 428-449

Coles AC 1914: Blood parasites found in mammals, birds, and fishes in England. Parasitology 7: 17-61

Cottontail VM, Kalko EK, Cottontail I, Wellinghausen N, Tschapka M, Perkins SL, Pinto CM 2014: High local diversity of Trypanosoma in a common bat species, and implications for the biogeography and taxonomy of the T. cruzi clade. Plos One 9: e108603

Ewald PW 1995: The evolution of virulence: A unifying link between parasitology and ecology. J Parasitol 81: 659-669

Gardner RA, Molyneux DH 1988: Schizotrypanum in British bats. Parasitology 97: 43-50 
Haitlinger R, Łupicki D 2008: Arthropods (Acari, Siphonaptera, Heteroptera, Psocoptera) associated with Nyctalus noctula (Schreber, 1774) (Chiroptera: Vespertilionidae) in Southern Poland. Wiad Parazytol 54: 123-130

Hall TA 1999: BioEdit: a user-friendly biological sequence alignment editor and analysis program for Windows 95/98/NT. Nucl Acids Symp Ser 41: 95-98

Hamilton PB, Cruickshank C, Stevens JR, Teixeira MM, Mathews F 2012: Parasites reveal movement of bats between the New and Old Worlds. Mol Phylogenet Evol 63: 521-526

Harshman LG, Zera AJ 2007: The cost of reproduction: the devil in the details. Trends Ecol Evol 22: 80-86

Howard EJ, Xiong X, Carlier Y, Sosa-Estani S, Buekens P 2014: Frequency of the congenital transmission of Trypanosoma cruzi: a systematic review and meta-analysis. BJOG 121: 22-23

Kopp R, Palíková M, Papežíková I, Mareš J, Navrátil S, Pikula J, Pohanka M 2018: Oxidative stress response of rainbow trout (Oncorhynchus mykiss) to multiple stressors Acta Vet Brno 87: 55-64

Lisboa CV, Pinho AP, Herrera HM, Gerhardt M, Cupolillo E, Jansen AM 2008: Trypanosoma cruzi (Kinetoplastida, Trypanosomatidae) genotypes in neotropical bats in Brazil. Vet Parasitol 156: 314-318

Lord JS 2010: Micro and macroparasites of bats (Chiroptera). Ph.D. thesis, University of Salford

Lord JS, Brooks DR 2014: Bat Endoparasites: A UK Perspective. In: Klimpel S, Melhorn H (Ed.): Bats (Chiroptera) as Vectors of Diseases and Parasites. Springer, pp. 63-86

Lozano IMD, De Pablos LM, Longhi SA, Zago MP, Schijman AG, Osuna A 2017: Immune complexes in chronic Chagas disease patients are formed by exovesicles from Trypanosoma cruzi carrying the conserved MASP N-terminal region. Sci Rep 7: 44451

Lucan RK, Bandouchova H, Bartonicka T, Pikula J, Zahradnikova A Jr, Zukal J, Martinkova N 2016: Ectoparasites may serve as vectors for the white-nose syndrome fungus. Parasit Vectors 9: 16

Molyneux DH 1991: Trypanosomes of Bats. In: Kreier JP, Baker JR (Eds): Parasitic Protozoa. Academic Press, New York, pp. 195-223

Muñoz J, Coll O, Juncosa T, Vergés M, del Pino M, Fumado V, Bosch J, Posada EJ, Hernandez S, Fisa R, Boguña JM, Gállego M, Sanz S, Portús M, Gascón J 2009: Prevalence and vertical transmission of Trypanosoma cruzi infection among pregnant Latin American women attending 2 maternity clinics in Barcelona, Spain. Clin Infect Dis 48: $1736-1740$

Petrie GF 1905: Observations relating to the structure and geographical distribution of certain trypanosomes. J Hyg 5: 191-200

Pikula J, Bandouchova H, Kovacova V, Linhart P, Piacek V, Zukal J 2017: Reproduction of rescued vespertilionid bats (Nyctalus noctula) in captivity: Veterinary and physiological aspects. Vet Clin North Am Exot Anim Pract 20: $665-677$

Ponte-Sucre A 2016: An Overview of Trypanosoma brucei infections: an intense host-parasite interaction. Front Microbiol 7: 2126

Postawa T, Gas A 2009: Do the thermal conditions in maternity colony roost determine the size of young bats? Comparison of attic and cave colonies of Myotis myotis in Southern Poland. Folia Zool 58: 396-408

Rambaut A 2010: FigTree v1.3.1. Institute of Evolutionary Biology, University of Edinburgh, Edinburgh. http://ree.bio.ed.ac.uk/software/figtree/

Ramírez JD, Tapia-Calle G, Muñoz-Cruz G, Poveda C, Rendón LM, Hincapié E, Guhl F 2014: Trypanosome species in neo-tropical bats: biological, evolutionary and epidemiological implications. Infect Genet Evol 22: 250-256

Ronquist F, Teslenko M, van der Mark P, Ayres D, Darling A, Hohna S, Larget B, Liu L, Suchard MA, Huelsenbeck JP 2012: MrBayes 3.2: Efficient Bayesian phylogenetic inference and model choice across a large model space. Syst Biol 61: 539-542

Seward EA, Votýpka J, Kment P, Lukeš J, Kelly S 2017: Description of Phytomonas oxycareni n. sp. from the salivary glands of Oxycarenus lavaterae. Protist 168: 71-79 